\title{
PENGARUH PUPUK ORGANIK CAIR (POC) URINE SAPI FERMENTASI TERHADAP TANAMAN JAGUNG HYBRID \\ (The Effects of organic fertilizer (POC) Fermented Cow Urine in Hybrid Corn)
}

\author{
Nuryanto and Sumaryanto \\ Sekolah Tinggi Penyuluhan Pertanian Magelang \\ Jl. Magelang-Kopeng Km 7 Purwosari Tegalrejo Magelang 56192 \\ Lecturer of STPP Magelang \\ (Email: stppnuryanto@gmail.com)
}

\begin{abstract}
This study done from September to December 2017 in Desa Pagersari, Mungkid, Magelang. Land area of 1,000 $\mathrm{m} 2$ divided by 36 plots, planted by hybrid corn $(70 \mathrm{~cm} 115$ $\mathrm{cm})$ which is two seeds per hole. When $10^{\text {th }}$ day after plant it fertilized by $10 \mathrm{~kg}$ of NPK, $7 \mathrm{~kg}$ of Urea, $4 \mathrm{~kg}$ of SP-36. When $28^{\text {th }}$ day after plant it randomly divide into 6 kinds of dosage treatment of POC fermented cow urine in $0 \mathrm{ml}, 100 \mathrm{ml}, 200 \mathrm{ml}, 300 \mathrm{ml}, 400 \mathrm{ml}$ and $500 \mathrm{ml}$ each tree and it repeated by 6 times. The variables refers by height of plant, Bagan Warna Daun (BWD), diameter of stem, harvest weight without klobot, dry weight of corn seed and weight each 100 seed.

Measurement results at $60^{\text {th }}$ day after plant, reach $284 \mathrm{~cm}$ height, $1.89 \mathrm{~cm}$ stem diameter and the BWD entered the category four.

The result show that hybrid corn that not fertilized by POC fermented cow urine (control) have harvest weight without klobot was $157 \mathrm{gr} / \mathrm{cob}$ that significantly different ( $P$ $<0.01)$ increased by $15.28 \%$ to $181 \mathrm{gr} / \mathrm{cob}$, dry weight of corn seed was $124 \mathrm{gr} / \mathrm{cob}$ that significantly different $(P<0.01)$ increased by $11.29 \%$ to $138 \mathrm{gr} / \mathrm{cob}$ and the weight each 100 seed was 24.33 gr that significantly different $(P<0.01)$ increased by $6.34 \%$ to $28 \mathrm{gr} / 100$ seed on hybrid corn that fertilized by POC fermented cow urine $100 \mathrm{ml} / \mathrm{stem}$.

In the fertilization more than $100 \mathrm{ml} / \mathrm{stem}$, there is likely to be an unstable increase $(P>0.05)$ to the harvest weight without klobot, dry weight corn seed and weight each 100 seeds. Based on this, for the efficiency and production of hybrid corn, the dose offertilization of both aged $28^{\text {th }}$ after plant with POC fermented cow urine is $100 \mathrm{ml} / \mathrm{stem}$.
\end{abstract}

Keywords: POC, hybrid corn

\begin{abstract}
ABSTRAK
Penelitian dilaksanakan September sampai dengan Desember 2017 di Desa Pagersari, Mungkid, Magelang. Tanah seluas $1.000 \mathrm{~m}^{2}$ dibagi 36 petak, ditanam jagung hibrid (70 x 15 $\mathrm{cm}$ ) dua benih per lobang. Umur 10 hst dipupuk NPK $10 \mathrm{~kg}$, urea $7 \mathrm{~kg}$, SP-36 sebanyak 4 $\mathrm{kg}$. Umur $28 \mathrm{hst}$, secara acak dibagi 6 macam perlakuan dosis pemupukan POC urine sapi fermentasi $0 \mathrm{ml}, 100 \mathrm{ml}, 200 \mathrm{ml}, 300 \mathrm{ml}, 400 \mathrm{ml}$ dan $500 \mathrm{ml} /$ batang dan diulang $6 \mathrm{kali}$. Variabel yang diamati tinggi tanaman, Bagan Warna Daun (BWD), diameter batang, bobot panen tanpa klobot, bobot kering jagung pipil dan bobot per 100 biji.
\end{abstract}


Hasil pengukuran pada umur $60 \mathrm{hst}$, rata-rata tinggi tanaman $284 \mathrm{~cm}$, diameter batang 1,89 cm dan Bagan Warna Daun masuk katagori empat.

Hasil panen menunjukkan bahwa, tanaman jagung yang tidak dipupuk POC urine sapi fermentasi (kontrol), bobot panen tanpa klobot $157 \mathrm{gr} /$ tongkol berbeda sangat nyata $(\mathrm{P}<$ $0,01)$ meningkat $15,28 \%$ menjadi $181 \mathrm{gr} /$ tongkol, bobot kering jagung pipil 124 gr/tongkol berbeda sangat nyata $(\mathrm{P}<0,01)$ meningkat $11,29 \%$ menjadi 138 gr/tongkol dan bobot jagung 100 biji 24,33 gr berbeda sangat nyata $(\mathrm{P}<0,01)$ meningkat $6,34 \%$ menjadi 28 gr/100 biji pada tanaman jagung yang dipupuk POC urine sapi fermentasi $100 \mathrm{ml} / \mathrm{batang}$.

Pada pemupukan lebih dari $100 \mathrm{ml} / \mathrm{batang}$, cenderung ada peningkatan yang tidak nyata $(\mathrm{P}>0,05)$ terhadap bobot panen tanpa klobot, bobot kering jagung pipil dan bobot 100 biji. Berdasar hal tersebut, untuk efisiensi dan produksi tanaman jagung hibrida, dosis pemupukan kedua umur 28 hst dengan POC urine sapi fermentasi adalah $100 \mathrm{ml} / \mathrm{batang}$.

Kata Kunci: POC, jagung hibrid

\section{PENDAHULUAN}

Pertumbuhan tanaman jagung dipengaruhi oleh genetik, cahaya, suhu, kelembaban, ketersediaan air dan zat hara tanah. Tetapi unsur hara yang diperlukan tanaman tidak seluruhnya dapat dipenuhi dari tanah, sehingga perlu penambahan dari luar guna mendorong pertumbuhan daun, akar, batang, bunga dan buah.

Pupuk Organik Cair (POC) urine sapi fermentasi, merupakan salah satu alternatif peningkatan ketersediaan dan kecukupan hara tanaman, sehingga dapat mengurangi penggunaan pupuk anorganik dan bahkan dapat meningkatkan hasil. Juliantoro, (2011) menyatakan bahwa, pupuk organik pada umumnya sudah cukup lengkap karena mengandung unsur makro dan mikro meskipun dalam jumlah sedikit. Razanni, Zulfita dan Anggorowati (2014) menyatakan bahwa, penggunaan POC urine sapi fermentasi sebagai pupuk tanaman dapat mengatasi permasalahan yang ditimbulkan oleh kekurangan pada pupuk anorganik. Penggunaan POC memberikan beberapa keuntungan, karena diaplikasikan dengan cara menyiramkannya ke akar tanaman, sehingga dapat menjaga kelembaban tanah.

\section{MATERI DAN METODE PENELITIAN a. Materi}

1. Tanah sawah luas $1.000 \mathrm{~m}^{2}$ di Desa Pagersari, Mungkid, Magelang;

2. Drum plastik, ember, tugal, Jerigen, sprayer, timbangan digital

3. Benih jagung hybrida

4. Pupuk NPK Phosphat, urea, SP-36, KCL dan POC urine sapi fermentasi.

\section{b. Metode}

1. Penelitian ini dilaksanakan selama 4 bulan (September sampai dengan Desember 2017) di Desa Pagersari, Mungkid, Magelang.

2. Tanah diolah dan dibagi menjadi 36 petak (masing-masing $12 \times 2,25 \mathrm{~m}$ ),

3. Dengan tugal, dibuat lobang tanam jarak baris $70 \mathrm{~cm}$ dan jarak dalam baris $15 \mathrm{~cm}$ untuk ditanami benih jagung Hibrid dua benih per lobang.

4. Umur 10 hst, tanaman jagung dipupuk kimia campuran yang terdiri dari NPK $10 \mathrm{~kg}$, Urea $7 \mathrm{~kg}$ dan SP-36 sebanyak $4 \mathrm{~kg}$

(Juliantoro, 2011).

5. Secara acak, 36 petak dibagi 6 macam perlakuan pemupukan diulang 6 kali. 
6. Pada umur $28 \mathrm{hst}$, tanaman jagung dipupuk dengan POC urine sapi fermentasi untuk enam macam dosis perlakuan pemupukan, yakni $0 \mathrm{ml}$, $100 \mathrm{ml}, 200 \mathrm{ml}, 300 \mathrm{ml}, 400 \mathrm{ml} \mathrm{dan}$ $500 \mathrm{ml}$ per batang.

7. Rancangan penelitian seperti tertera pada Tabel 1 katagori 4. Ekowati dan Masir (2011) melaporkan bahwa, rata rata tinggi tanaman jagung 156,35 $\mathrm{cm}$ dan diameter batangnya $3,34-4,03 \mathrm{~cm}$. Saputra (2013) menyatakan bahwa, rata-rata diameter batang adalah 3,12 $\mathrm{cm}$.

Hasil analisa uji beda menunjukkan bahwa, pemupukan dengan POC urine sapi

Tabel 1. Rancangan penelitian Pengaruh Pemupukan dengan POC urin sapi fermentasi terhadap produktivitas tanaman jagung

POC urine Sapi Fermentasi (ml/batang)

100

200

300

400

500

)

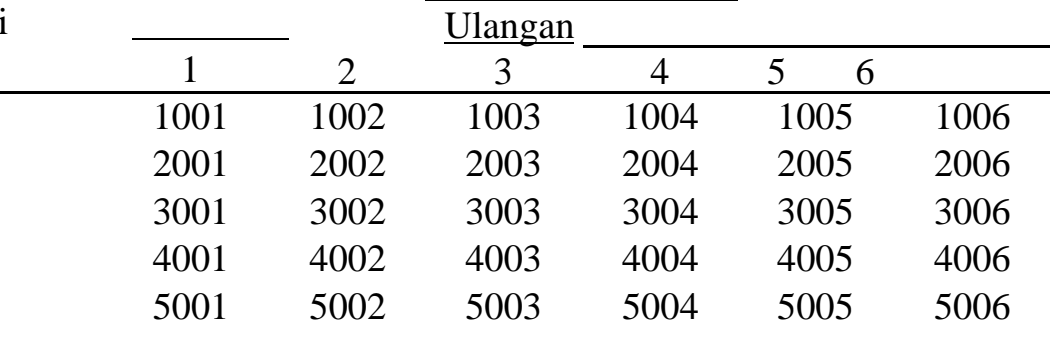

8. Variabel yang diamati adalah: tinggi tanaman, Bagan Warna Daun (BWD) dan diameter pangkal batang, bobot panen tanpa klobot, berat kering jagung pipil dan berat per 100 biji.

9. Data hasil dianalisis dengan Rancangan Acak Lengkap (RAL) pola factorial (6 $\mathrm{X}$ 6) dan untuk uji kepastiannya digunakan Duncan's Multiple Range Test

(Hanafiah, 2005).

\section{HASIL DAN PEMBAHASAN}

\section{Tinggi Tanaman dan Diameter Batang}

Biba (2014) menyatakan bahwa, standart kepadatan tanaman jagung setiap hektar adalah 71.000 sampai 83.000 batang/hektar. Pada penelitian ini, tanah seluas $1.000 \quad \mathrm{~m}^{2}$ ditanam 2 benih jagung/lobang (jarak tanam $70 \mathrm{~cm}$ dan jarak baris $15 \mathrm{~cm}$ ) jumlah tanaman mencapai 9.808 batang. Sehingga pada penelitian ini jumlah tanamannya termasuk rapat, tanaman subur, tinggi tanaman umur 60 hst mencapai $284 \mathrm{~cm}$, tetapi diameter batangnya kecil, yakni rataratanya $1,89 \mathrm{~cm}$ dan bagan warna daun masuk fermentasi pada umur 28 hst sebanyak 0 $\mathrm{ml} /$ batang, $100 \mathrm{ml} /$ batang, $200 \mathrm{ml} /$ batang, $300 \mathrm{ml} /$ batang, $400 \mathrm{ml} /$ batang dan 500 $\mathrm{ml} /$ batang, ada kecenderungan meningkatkan tinggi tanaman dan diameter batang, tetapi peningkatannya masingmasing perlakuan tidak nyata $(\mathrm{P}>$ 0,05). Tingginya tanaman dan kecilnya diameter batang tanaman jagung pada penelitian ini diduga disebabkan karena jagung ditanam di tanah sawah, jenis tanah andosol (tanah vulkanik yang kaya akan mineral dan unsur hara), musim penghujan, jarak tanam rapat $(70 \times 15 \mathrm{~cm})$ dengan dua tanaman per lobang, pemupukan tepat waktu terdiri dari kombinasi antara pupuk anorganik dan organic. Sitompul dan Guritno (1995) menyatakan bahwa, pada tanaman yang rapat, bagian yang kurang mendapat cahaya, proses fotosintesa tidak maksimal, batang tanaman menjadi kecil dan tinggi. Erawati dan Hipi (2016) menyatakan bahwa, jarak tanam berpengaruh nyata terhadap tinggi tanaman, pada jarak tanam yang rapat cenderung tanaman menjadi tinggi, karena ruang gerak tanaman 
terbatas, sehingga tanaman akan berusaha untuk mencari sinar matahari dengan memperpanjang organ. Tingginya tanaman jagung dan kecilnya diameter batang diduga kurang diminati petani karena perlu tambahan dana dan tenaga kerja untuk memasang ajir dan mengikatnya guna menghindari robohnya tanaman.

\section{Bobot Panen Tanpa Klobot}

Hasil penelitian menunjukkan bahwa, rata-rata bobot panen tanpa kolobot adalah 181,48 gr/tongkol. Pemupukan tanaman jagung hibrid umur 10 hst dengan NPK $10 \mathrm{~kg}$, urea $7 \mathrm{~kg}$ dan SP-36 sebanyak $4 \mathrm{~kg}$ dan pada umur $28 \mathrm{hst}$ dipupuk dengan POC urine sapi fermentasi sebanyak 0, 100, 200, 300, 400 dan $500 \mathrm{ml} /$ batang, sangat nyata $(\mathrm{P}<0,01)$ berpengaruh terhadap bobot panen tanpa klobot. Ekowati dan Nasir (2011) menyatakan bahwa, rata-rata bobot panen tanpa klobot adalah 153,06 gr/tongkol). Kaya dkk. (2016) melaporkan bahwa, pemberian pupuk kompos 60 ton per hektar menghailkan bobot tongkol 198,33 gram/tongkol. Razanni, Zulfita dan Anggorowati (2014) menyatakan bahwa, penambahan urine sapi pada tanaman jagung yang dipupuk anorganik dengan dosis $50 \%$ dapat memberikan hasil yang terbaik yakni, rata-rata bobot jagung tanpa klobot adalah 177,54 gr/tongkol. Tingginya bobot panen tanpa klobot pada penelitian ini, diduga disebabkan karena jenis tanahnya subur, air tersedia, pemupukan kombinasi anorganik dan organik tepat waktu.

Hasil analisa statistik menunjukan bahwa, tanaman jagung yang tidak dipupuk dengan POC urine sapi fermentasi, menghasilkan bobot panen tanpa klobot 157 gr/tongkol berbeda sangat nyata $(\mathrm{P}<0,01)$ meningkat $(15,28 \%)$ menjadi 181 gr/tongkol pada tanaman jagung yang dipupuk dengan POC urin sapi fermentasi $100 \mathrm{ml} /$ batang. Tetapi pemupukan urine sapi fermentasi lebih dari $100 \mathrm{ml} / \mathrm{batang}$, cenderung dapt meningkatkan bobot panen tanpa klobot, tetapi masing-masing tidak menunjukkan perbedaan yang nyata $(\mathrm{P}>0,05)$. Hal ini diduga disebabkan karena pemupukan POC urine sapi fermentasi $100 \mathrm{ml} /$ batang telah dapat melengkapi unsur hara tanaman yang tidak dipunyai oleh pupuk anorganik atau mungkin penambahan POC urine sapi fermentasi yang lebih dari $100 \mathrm{ml} / \mathrm{batang}$ tidak langsung dapat diserap akar tanaman atau mungkin kemampuan akar untuk menyerap hara tanaman terbatas. Oleh karena itu, pemupukan kedua pada tanaman jagung lebih dari $100 \mathrm{ml} /$ batang, dianggap kurang efisien. Adapun pengaruh penambahan POC

Tabel 2. Pengaruh pemupukan POC urin sapi fermentasi $0 \mathrm{ml} / \mathrm{batang}, 100 \mathrm{ml} / \mathrm{batang}, 200$ $\mathrm{ml} /$ batang, $300 \mathrm{ml} /$ batang, $400 \mathrm{ml} /$ batang dan $500 \mathrm{ml} /$ batang terhadap Bobot Panen tanpa klobot.

\begin{tabular}{cc}
\hline \hline $\begin{array}{c}\text { Pemupukan } \\
\text { dengan P0C } \\
(\mathrm{ml} / \text { batang) }\end{array}$ & $\begin{array}{c}\text { Rerata bobot panen tanpa } \\
\text { klobot } \\
\text { (gr/tongkol) }\end{array}$ \\
\hline 0 & $157_{\mathrm{a}}$ \\
100 & $181_{\mathrm{b}}$ \\
200 & $185_{\mathrm{b}}$ \\
300 & $186_{\mathrm{b}}$ \\
400 & $187_{\mathrm{b}}$ \\
500 & $190_{\mathrm{b}}$ \\
\hline
\end{tabular}

Keterangan: Subskrib yang berbeda pada kolom rerata, Uji DMRT menunjukan perbedaan $(\mathrm{P}<0,01)$.

Pengaruh penambahan limbah ampas tahu pada Feses sapi terhadap produksi metan, kecernaan 
urine sapi fermentasi $0 \mathrm{ml} / \mathrm{batang}, 100$ $\mathrm{ml} /$ batang, $200 \mathrm{ml} /$ batang, $300 \mathrm{ml} /$ batang, 400 $\mathrm{ml} /$ batang dan $500 \mathrm{ml} /$ batang terhadap bobot panen tanpa klobot dapat dilihat pada Tabel 2.

\section{Bobot kering Jagung Pipil}

Hasil penelitian menunjukkan bahwa, rata-rata bobot kering jagung pipil adalah 140,17 gr/tongkol. Pemupukan tanaman jagung hibrid umur 10 hst dengan NPK $10 \mathrm{~kg}$, urea $7 \mathrm{~kg}$ dan SP-36 sebanyak $4 \mathrm{~kg}$ dan pada umur 28 hst dipupuk dengan POC urine sapi fermentasi sebanyak 0, 100, 200, 300, 400 dan $500 \mathrm{ml} /$ batang, sangat nyata $(\mathrm{P}<0,01)$ berpengaruh terhadap bobot kering jagung pipil. Yuniastuti dkk. (2008) menyatakan bahwa, bobot jagung pipil kering yang dilakukan petani adalah 102 gr/tongkol dan dengan teknologi budidaya mencapai 160 gr/tongkol. Ekowati dan Nasir (2011) menyatakan bahwa produksi jagung pipil kering adalah 119,24 per tongkol. Razanni, Zulfita dan Anggorowati (2014) menyatakan bahwa, penambahan urine sapi pada tanaman jagung yang dipupuk anorganik dengan dosis $50 \%$ dapat memberikan hasil yang terbaik yakni, rata-rata bobot pipilan kering sebanyak 139,05 gr/tongkol).

\section{Bobot 100 Biji}

Tabel 3. Pengaruh penambahan pupuk cair urin sapi fermentasi $0 \mathrm{ml} / \mathrm{batang}, 100 \mathrm{ml} / \mathrm{batang}$, $200 \mathrm{ml} /$ batang, $300 \mathrm{ml} /$ batang, $400 \mathrm{ml} /$ batang dan $500 \mathrm{ml} /$ batang terhadap Bobot kering jagung pipil.

POC Urine sapi Fermentasi

(ml/batang)

\begin{tabular}{cc} 
(ml/batang) & Rerata bobot kering jagung pipil (kg/tongkol) \\
\hline 0 & $124_{\mathrm{a}}$ \\
100 & $138_{\mathrm{b}}$ \\
200 & $143_{\mathrm{b}}$ \\
300 & $144_{\mathrm{b}}$ \\
400 & $145_{\mathrm{b}}$ \\
500 & $147_{\mathrm{b}}$ \\
\hline
\end{tabular}

Keterangan: Subskrib yang berbeda pada kolom rerata, Uji DMRT menunjukan perbedaan (P $<0,01)$

Hasil penelitian menunjukkan bahwa, jagung hybrid umur 10 hst dengan NPK $10 \mathrm{~kg}$, rata-rata bobot 100 biji jagung pipil kering urea $7 \mathrm{~kg}$ dan SP-36 sebanyak $4 \mathrm{~kg}$ dan pada 
umur 28 hst dipupuk dengan POC urine sapi fermentasi sebanyak 0, 100, 200, 300, 400 dan $500 \mathrm{ml} /$ batang, sangat nyata ( $\mathrm{P}<0,01)$ berpengaruh terhadap bobot 100 biji jagung pipil kering. Yuniastuti dkk (2008) menyatakan bahwa, rata-rata bobot 100 biji jagung pipil kering dilakukan petani adalah 23,76 gram dan dengan teknologi mencapai 29,03 gram. Etica dan Hamawi (2016) meyatakan bahwa, ratarata bobot 100 biji jagung pipil kering adalah 31,61 - 35,67 gram. Razanni, Zulfita dan Anggorowati (2014) menyatakan bahwa, penambahan urine sapi tanaman. Sutejo, (2002) menyatakan bahwa, penggunaan POC sebagai pupuk dapat memperbaiki sifat fisika, kimia, biologi tanah sehingga dapat meningkatkan produksi tanaman karena mengandung unsur hara makro dan mikro esensial, yakni N, P, K, S, Ca, Mg, B, Mo, Cu, Fe dan $\mathrm{Mn}$.

Pemupukan POC urine sapi fermentasi $100 \mathrm{ml}$ per batang sampai dengan $500 \mathrm{ml}$ per batang ada kecenderungan peningkatan yang tidak nyata $(\mathrm{P}>0,05)$. Hal ini diduga disebabkan karena pemupukan dengan POC Tabel 3. Pengaruh penambahan pupuk cair urin sapi fermentasi $0 \mathrm{ml} / \mathrm{batang}, 100$ $\mathrm{ml} / \mathrm{batang}, 200 \mathrm{ml} / \mathrm{batang}, 300 \mathrm{ml} /$ batang, $400 \mathrm{ml} / \mathrm{batang}$ dan $500 \mathrm{ml} / \mathrm{batang}$ terhadap Berat Jagung Pipil per 100 biji.

\begin{tabular}{|c|c|}
\hline POC Urine sapi Fermentasi (ml/batang) & $\begin{array}{l}\text { Rerata bobot } 100 \text { biji jagung pipil } \\
\text { (biji/tongkol) }\end{array}$ \\
\hline 0 & $26.33_{\mathrm{a}}$ \\
\hline 100 & $28.00_{\mathrm{b}}$ \\
\hline 200 & $28.17_{\mathrm{b}}$ \\
\hline 300 & $27.83_{\mathrm{b}}$ \\
\hline 400 & $28.00_{\mathrm{b}}$ \\
\hline 500 & $28.50_{\mathrm{b}}$ \\
\hline
\end{tabular}

Keterangan: Subskrib yang berbeda pada kolom rerata, Uji DMRT menunjukan perbedaan (P $<0,05)$

pada tanaman jagung yang dipupuk anorganik dosis $50 \%$, dapat memberikan hasil yang terbaik, yakni bobot 100 biji adalah 30,87 gram.

Dengan uji beda, tanaman jagung yang tanpa dipupuk dengan POC urine sapi fermentasi $100 \mathrm{ml} /$ batang, rata-rata bobot 100 biji jagug pipil kering sebanyak 26,33 gr berbeda sangat nyata $(\mathrm{P}<0,01)$ meningkat $6,34 \%$ menjadi 28,00 gr. Hal ini diduga disebabkan karena pemupukan POC urine sapi fermentasi telah dapat melengkapi unsur hara yang dibutuhkan KESIMPULAN

Jagung hybrid yang ditanam rapat 2 benih/lobang, jarak tanam $70 \times 15 \mathrm{~cm}$, dalam $1000 \mathrm{~m}^{2}$ jumlah tanamannya mencapai 9.808 batang. Dipupuk anorganik urine sapi fermentasi pada tanaman jagung lebih dari $100 \mathrm{ml} / \mathrm{batang}$ tidak dapat langsung diserap oleh akar atau mungkin kemampuan akar untuk menyerap hara tanaman terbatas. Oleh karena itu, pemupukan tanaman jagung lebih dari $100 \mathrm{ml} / \mathrm{batang}$ dianggap kurang efisien. Adapun pengaruh penambahan pupuk cair urin sapi fermentasi $0 \mathrm{ml} /$ batang, 100 $\mathrm{ml} /$ batang, $200 \mathrm{ml} / \mathrm{batang}, 300 \mathrm{ml} / \mathrm{batang}, 400$ $\mathrm{ml} /$ batang dan $500 \mathrm{ml} /$ batang terhadap Berat Jagung

Pipil per 100 biji dapat dilihat pada Tabel 3.

dan POC urine sapi fermentasi, tanaman jagung termasuk subur (BWD 4), dimeter batang $1,89 \mathrm{~cm}$ dan tinggi tanaman mencapai $284 \mathrm{~cm}$. 
Pemupukan dengan POC urin sapi fermentasi sangat nyata $(\mathrm{P}<0,01)$ dapat meningkatkan bobot panen tanpa klobot 
$15,28 \%$ (dari 157 gr/tongkol menjadi 181 gr/tongkol), bobot kering jagung pipil sebanyak $11,29 \%$ (dari 124 gr/tongkol menjadi 138 gr/tongkol) dan bobot 100 biji meningkat $6,34 \%$ (dari 26,33 gr menjadi 28,00 gr) pada tanaman jagung yang dipupuk dengan POC urine sapi fermentasi $100 \mathrm{ml} /$ batang. Namun pemupukan lebih dari $100 \mathrm{ml} /$ batang menunjukkan kecenderungan yang meningkat tidak nyata $(\mathrm{P}>0,05)$ terhadap bobot panen tanpa klobot, bobot kering jagung pipil dan bobot 100 biji.

\section{DAFTAR PUSTAKA}

Biba M.A. (2015). Pengaruh Jarak Tanam dan Varietas Jagung Hibrida terhadap Pendapatan Petani, Balai Penelitian Tanaman Serealia, Sulawesi Selatan Prosiding Seminar Nasional Serealia, 2015. http://balit sereal.litbang.pertanian.go.id/wp content/uploads/2018/01/15se89. pdf

Ekowati D. dan M.

Nasir., 2011. Pertumbuhan

Tanaman Jagung (Zea mays L)

Varietas BISI-2 Pada Pasir

Rejeck dan Pasir Asli di Pantai

Trisik, Kulon Progo. Fakultas Biologi, Universitas Gadjah Mada, Yogyakarta. Jurnal Manusia dan Lingkungan Vol.18, No 3. Nov

2011: 220 - 231.

Erawati B.T.R. dan Hipi A. (2016).

Pengaruh Jarak Tanam terhadap

Pertumbuhan dan Hasil

Beberapa Varietas Jagung

Hibrida di Kawasan

Pengembangan Jagung
Kabupaten Sumbawa. Balai Pengkajian Teknologi Pertanian Nusa Tenggara Barat. Prosiding Seminar Nasional Inovasi Teknologi Pertanian, Banjarbaru, 20 Juli 2016

http://kalsel.litbang.pertanian.go.id/i nd/images/pdf/Semnas2016/74_baiq _tri.pdf

Etica E. dan M. Hamawi. 2016. Pengaruh Metode Tanam Lingkar Berjajar dan Varietas Jagung Hibrida Terhadap Produksi Jagung (Zea mays L). Program Studi Agrotecknologi Universitas Darussalam Gontor, Ponorogo. Agroteck Science

Journal, vol 2. No 2 Juni 2016.

Hanafiah K.A. 2005. Rancangan Percobaan Teori dan Apikasi. Jakarta, PT

Rajawali Pers. Edisi ketiga, Jakarta..

Juliantoro, M. 2011. Pengaruh Pupuk terhadap

Tanaman. Diambil dari http://mohamadjuliantoro.blogspot.

com/2011/10/pengaruh pupukterhadap-tanaman.html

Razanni, Zulfita D., Anggorowati D., 2014. Pengaruh Campuran Urine dengan Kotoran Sapi yang

Terfermentasi dan Pemupukan Urea, SP36, KCL Terhadap Pertumbuhan dan Hasil Tanaman Jagung Pada Tanah Alluvial, Jurnal Lahan Suboptimal ISSN: 2252-6188 (Print), ISSN: 23023015.Online,

http://jurnal.untan.ac.id/index.php/j spp/article/view/1197,Agustus2017

Yuniastuti S., Suhardi, E. Retnaningtyas, L.

Amalia dan A. Rosyid (2008).

Peningkatan Hasil dan Mutu Jagung Hibrida (Zea mays) melalui perbaikan Teknologi Budidaya. Prosiding seminar Hasil Penelitian/ Pengkajian, BPTP Karangploso, Jatimhttp://jatim.litbang.pertanian.g o.id/ind/phocadownload/Prosiding/ 
PENINGKATAN\%2OHASIL\%20

DAN\%20MUTU\%20JAGUNG\%

20HIBRIDA\%20Zea\%20mays\%

20MELALUI\%2OPERBAIKAN\%

20TEKNOLOGI\%2OBUDIDAYA

.$p d f$ 